\title{
Evaluating the Incidence of Opioid-Induced Respiratory Depression Associated with Oliceridine and Morphine as Measured by the Frequency and Average Cumulative Duration of Dosing Interruption in Patients Treated for Acute Postoperative Pain
}

\author{
Sabry Ayad ${ }^{1,4}$ (1) $\cdot$ Mark A. Demitrack ${ }^{2} \cdot$ David A. Burt $^{3} \cdot$ Cathy Michalsky $^{3} \cdot$ Linda Wase $^{2} \cdot$ Michael J. Fossler $^{3}$. \\ Ashish K. Khanna ${ }^{4,5}$
}

Published online: 24 June 2020

(c) The Author(s) 2020

\begin{abstract}
Background and Objective Opioid-induced respiratory depression (OIRD) is a potentially fatal complication associated with conventional opioids. Currently, there is a paucity of validated endpoints available to measure respiratory safety. Oliceridine, an investigational intravenous (IV) opioid, is a G-protein selective $\mu$-agonist with limited activity on $\beta$-arrestin2, a signaling pathway associated with adverse events including OIRD. In controlled phase III trials, oliceridine $0.35 \mathrm{mg}$ and $0.5 \mathrm{mg}$ demand doses demonstrated comparable analgesia to morphine $1 \mathrm{mg}$ with favorable improvements in respiratory safety. In this exploratory analysis, we report dosing interruption (DI) and average cumulative duration of DI (CDDI) for both oliceridine and morphine.

Methods Patients requiring analgesia after bunionectomy or abdominoplasty were randomized to IV demand doses of placebo, oliceridine $(0.1 \mathrm{mg}, 0.35 \mathrm{mg}$, or $0.5 \mathrm{mg})$, or morphine $(1 \mathrm{mg})$, administered via patient-controlled analgesia (PCA), following a loading dose (oliceridine $1.5 \mathrm{mg}$, morphine $4 \mathrm{mg}$, volume-matched placebo) with a 6-min lockout interval. Certified nurse anesthetists monitored each patient and withheld study medication according to the patient's respiratory status. For each patient, the duration of all DIs was summed and reported as CDDI. A zero-inflated gamma mixture model was used to compute the mean CDDI for each treatment.

Results Proportion of patients with DI was lower with oliceridine (0.1 mg: 3.2\%, $0.35 \mathrm{mg}: 13.9 \%, 0.5 \mathrm{mg}: 15.1 \%)$ versus morphine (22\%). The CDDI was also lower across all demand doses of oliceridine versus morphine.

Conclusion Using DI as a surrogate for OIRD indicates improved respiratory safety with oliceridine versus morphine that merits further investigation.
\end{abstract}

Electronic supplementary material The online version of this article (https://doi.org/10.1007/s40261-020-00936-0) contains supplementary material, which is available to authorized users.

Sabry Ayad

Saayad@ccf.org

1 Department of Anesthesiology, Cleveland Clinic, Outcomes Research, Anesthesiology Institute, Fairview Hospital, 18101 Lorain Avenue, Cleveland, OH 44111, USA

2 Clinical Operations and Medical Affairs, Trevena Inc., Chesterbrook, PA, USA

3 Clinical Development and Quantitative Sciences, Trevena Inc., Chesterbrook, PA 19087, USA

4 Department of Anesthesiology, Wake Forest School of Medicine, Winston-Salem, NC, USA

5 Outcomes Research Consortium, Cleveland, OH, USA 


\section{Key Points}

Data for 790 patients from two phase III randomized, active, and placebo-controlled studies that evaluated oliceridine (with active comparator morphine) in acute post-surgical pain following either bunionectomy or abdominoplasty were analyzed to determine the dosing interruption (DI) resulting due to postoperative opioidinduced respiratory depression.

Findings show that the proportion of patients with dosing interruption due to a respiratory event as well as the cumulative duration of dosing interruption was lower across all demand doses of oliceridine than observed with morphine.

The exploratory findings suggest improved respiratory safety with the G-protein selective opioid agonist oliceridine.

\section{Introduction}

Opioids are an integral component of multimodal analgesia for the management of moderate to severe postoperative acute pain [1, 2]. However, conventional opioids are associated with adverse events, including postoperative opioidinduced respiratory depression (OIRD). This is a serious medical complication and may have devastating consequences including anoxic brain injury and mortality in the hospital setting [3, 4]. Effective monitoring and appropriate interventions, including dose interruption or discontinuation of opioids, and the use of supplemental oxygen are strategies employed to facilitate safer use of opioids for pain management [5].

Oliceridine (TRV130; Trevena Inc., Chesterbrook, PA, USA) is an investigational intravenous (IV) opioid representing a next-generation $\mu$-agonist $[6,7]$ with selective and preferential activation of G-protein signaling and markedly reduced $\beta$-arrestin 2 recruitment compared with conventional opioids $[8,9]$. Theoretically, due to the low recruitment of $\beta$-arrestin2, oliceridine would be expected to provide potent analgesia with a reduced occurrence of adverse events, including OIRD [6, 7]. Preclinical studies and early clinical trials demonstrated equal or greater analgesia with less impairment in respiratory drive with oliceridine than morphine $[7,10]$.

Recently, two phase III randomized, placebo- and active comparator-controlled clinical trials evaluated oliceridine in acute post-surgical pain following either bunionectomy or abdominoplasty [11, 12]. Both studies utilized a composite secondary endpoint, "respiratory safety burden" (RSB), defined as the mathematical product of the prevalence of respiratory safety events (RSE defined as changes in respiratory rate, or oxygen saturation, or somnolence/sedation measured using the Moline-Roberts Pharmacologic Sedation Scale) and their cumulative duration, to measure respiratory safety. Results showed a reduction in RSB with oliceridine compared to morphine; however, statistical significance was reached only for the lowest dose of oliceridine used in both studies. RSB as designed proved to be a challenging endpoint to measure due to reliance on subjective clinical assessments of both RSEs and their duration, and statistically indeterminate results for some of the oliceridine doses studied.

We hypothesized that the methodology for detecting evidence of respiratory safety with oliceridine may be improved from these phase III studies. Specifically, we sought to determine whether the potential clinically important and distinguishable respiratory safety profile of oliceridine compared to morphine could be further elucidated based on objective indices of specific clinical interventions utilized for the management of postoperative OIRD. In this post hoc analysis of the controlled phase III trials, we report on the frequency and average cumulative duration of dosing interruption (CDDI), due to a respiratory event of both oliceridine and morphine. This serves as an objective surrogate endpoint, indicating the presence of a clinically important respiratory safety event.

\section{Methods}

The study design and the results for the two phase III randomized, controlled clinical trials evaluating oliceridine in acute pain models of bunionectomy and abdominoplasty, have been reported in detail elsewhere [11, 12]. Both studies were conducted in compliance with the Declaration of Helsinki and the International Council on Harmonisation Good Clinical Practice Guidelines. The trial protocol was approved by a centralized institutional review board and all patients provided written informed consent before any study procedures were performed $[11,12]$.

\subsection{Study Design}

Eligible patients aged 18-75 years, with a body mass index $(\mathrm{BMI}) \leq 35 \mathrm{~kg} / \mathrm{m}^{2}$ and body weight $\geq 40 \mathrm{~kg}$, and who had undergone primary surgery of either bunionectomy (hard tissue) or abdominoplasty (soft tissue), with moderate-to-severe pain as measured by the numeric rating scale (NRS) $[\mathrm{NRS} \geq 4$ for the bunionectomy study and NRS $\geq 5$ for the abdominoplasty study] were randomized to receive IV demand-dose 
regimens of placebo, oliceridine $0.1 \mathrm{mg}$, oliceridine $0.35 \mathrm{mg}$, oliceridine $0.5 \mathrm{mg}$, or morphine $1 \mathrm{mg}$. For each regimen, a clinician-administered IV fixed loading dose (oliceridine $1.5 \mathrm{mg}$, morphine $4 \mathrm{mg}$, or volume-matched placebo) was followed by demand doses administered via a patient-controlled analgesia (PCA) device and clinician-administered, blinded supplemental doses. PCA doses were allowed from $10 \mathrm{~min}$ after the loading dose and limited by a 6-min lockout interval. Blinded clinician-administered IV supplemental doses (oliceridine $0.75 \mathrm{mg}$ and morphine $2 \mathrm{mg}$ ) were permitted as often as hourly (PRN) (Supplemental Online Material, Fig. 1).

\subsection{Respiratory Safety Events}

Patients were monitored during the randomized treatment period ( $48 \mathrm{~h}$ for the hard tissue surgery and $24 \mathrm{~h}$ for the soft tissue surgery) on a protocol-defined schedule by the monitoring clinician caring for the patient (either a certified registered nurse anesthetist or an anesthesiologist blinded to study medication assignment). A respiratory safety event (RSE) was prospectively defined as a clinically relevant worsening of respiratory status, as determined by the monitoring clinician. The monitoring professional combined clinical acumen with objective clinical measures (e.g., respiratory rate, $\mathrm{O}_{2}$ saturation, somnolence/sedation using Moline Roberts scale) to determine if and when respiratory status was compromised, and intervened by taking away the patient's dosing button. The length of time the button was taken away varied from patient to patient and depended on the severity of the RSE. Once the clinician was satisfied that the RSE was resolved, the dosing button was returned. The time that the button was taken (onset of RSE) as well as the time it was returned (resolution) was recorded. Interventions also included provision of supplemental oxygen. During this time, patients could request rescue pain medication if needed (etodolac $200 \mathrm{mg}$ every $6 \mathrm{~h}$ as needed). As per protocol, if a patient received any rescue pain medicine, they were designated as a treatment failure for purposes of the study but continued to be monitored and treated.

For this post hoc analysis, including pooled data from both studies, we analyzed: (a) the frequency of dosing interruptions (DI) for each patient, (b) the proportion of patients with DI due to an RSE, and (c) the duration of all DIs that were summed and reported as the CDDI. In addition, we also report the relative risk reductions in the incidence of oxygen desaturations $<90 \%$ as well as discontinuations due to a respiratory event for the oliceridine and morphine regimens. Pooled data from the two randomized controlled clinical trials were also analyzed. Safety comparisons to morphine are most relevant at the two demand-dose regimens of oliceridine $0.35 \mathrm{mg}$ and $0.5 \mathrm{mg}$ since these two dose regimens were shown to provide comparable analgesia to morphine, as demonstrated by categorical responder rates $[11,12]$.

\subsection{Statistical Analysis}

The CDDI was computed for each patient, where patients who did not experience an RSE were considered to have a cumulative duration of $0 \mathrm{~h}$, and were modeled using a zeroinflated gamma distribution. The expected cumulative duration of study medication dosing interruptions was estimated and compared between treatment groups.

For patients who had a permanent interruption, the time from the start of the permanent interruption until the end of the treatment period ( $48 \mathrm{~h}$ for bunionectomy study and $24 \mathrm{~h}$ for abdominoplasty study) was included in the calculation of the duration of interruptions for the patient. Additionally, in both studies if a patient had a temporary interruption that "timed out" at the end of the randomized treatment period, the time from the start of the temporary interruption to the end of the randomized treatment period was included in the calculation of the duration of interruptions for the patient.

The number of study medication DIs and the percentage of patients with study medication DIs are presented by treatment group. Individual dosing patterns and interruptions were examined by a nominal dose for each patient. Descriptive statistics are provided for pooled data and, where possible, the associated $95 \%$ confidence interval $(\mathrm{CI})$ is provided.

\section{Results}

In both studies, the treatment regimens were generally balanced for age, race, and baseline characteristics. The mean age of patients was 45 years in the hard tissue study and 41 years in the soft tissue study, with mostly female patients (84.8\%, hard tissue and 99.3\%, soft tissue) and predominantly Caucasian (69\%, hard tissue and 64\%, soft tissue). The mean BMI was $26.5 \mathrm{~kg} / \mathrm{m}^{2}$ and $27.3 \mathrm{~kg} / \mathrm{m}^{2}$ in the hard tissue and soft tissue studies, respectively. Patients enrolled in either study did not have a history of postoperative nausea or vomiting or sleep apnea, and no patients had chronic obstructive pulmonary disease. In the pooled data set, there were a total of 790 subjects: placebo $-n=162$, oliceridine $0.1 \mathrm{mg}-n=153,0.35 \mathrm{mg}-n=158$, or $0.5 \mathrm{mg}-n=159$, and morphine $1 \mathrm{mg}-n=158$. Mean baseline pain scores using the Numeric Rating Scale (NRS) in patients after the bunionectomy surgery and in patients after the abdominoplasty surgery were 6.7 and 7.3 , respectively. The efficacy and safety results have been previously reported for the individual studies $[11,12]$. In both studies, the proportion of responders among oliceridine $0.1 \mathrm{mg}, 0.35 \mathrm{mg}$, and $0.5 \mathrm{mg}$ dose regimens was significantly greater compared to placebo. In addition, the oliceridine $0.35 \mathrm{mg}$ and $0.5 \mathrm{mg}$ dose regimens achieved comparable levels of analgesia to the morphine $1 \mathrm{mg}$ demand-dose regimen as measured by the primary outcome criterion in those studies (Fig. 1). In 

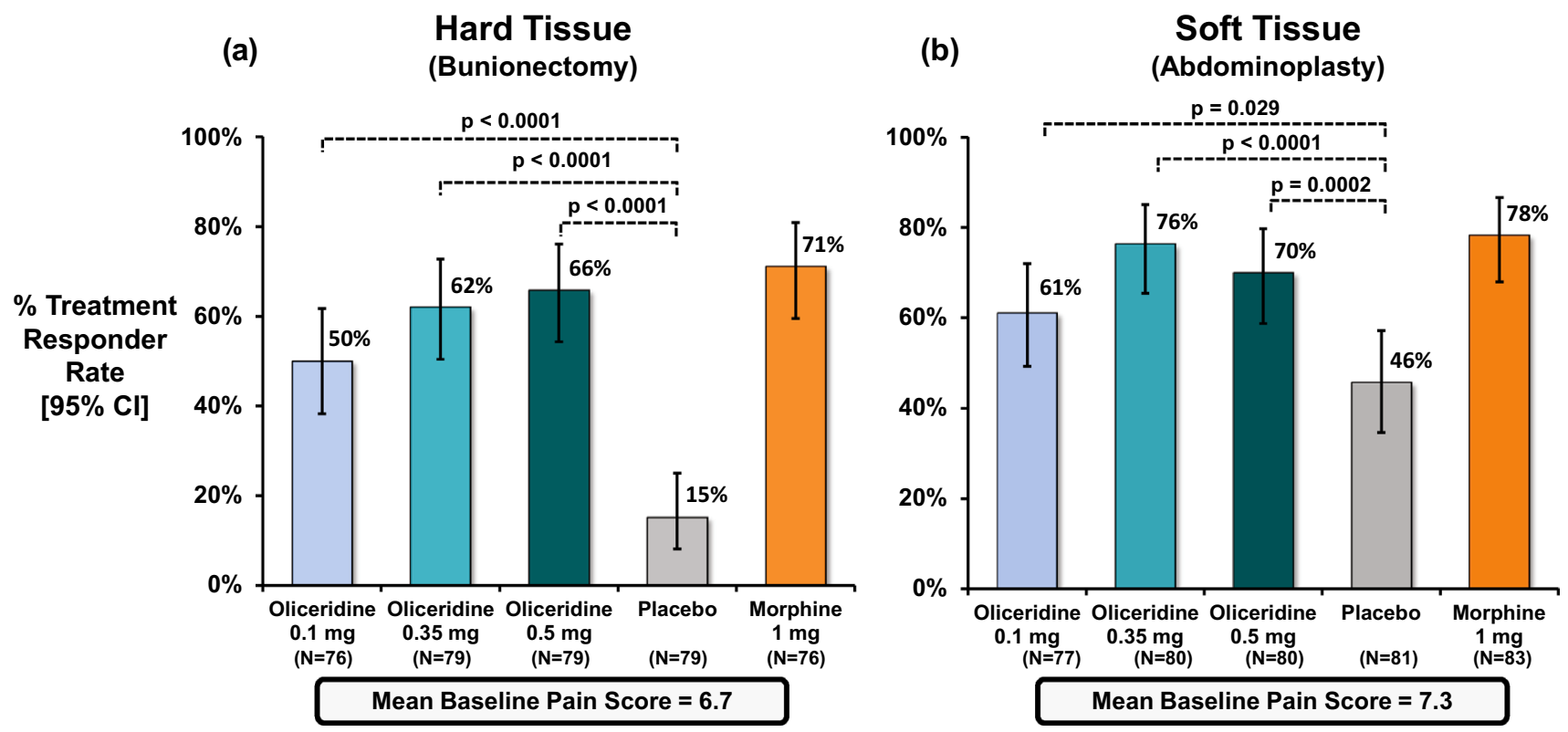

Fig. 1 Primary treatment response from controlled phase III trials. The primary endpoint analysis compared the percentage of treatment responders in each oliceridine regimen with the percentage of responders in the placebo regimen. a Hard tissue (bunionectomy) study and b soft tissue (abdominoplasty) study. The duration in the hard tissue (bunionectomy) study was $48 \mathrm{~h}$ and in the soft tissue (abdominoplasty) study was $24 \mathrm{~h}$. A patient was considered a treatment responder if all the following conditions were met: at least

both studies, oliceridine showed an improved safety profile in respiratory and gastrointestinal adverse events compared to morphine $[11,12]$.

\subsection{Exposure to Treatment}

The cumulative exposure to oliceridine was greater with the higher demand-dose regimens (Table 1), though the mean a 30\% improvement in their final time-weighted sum of pain intensity difference (SPID) from baseline at $48 \mathrm{~h}$ (for bunionectomy) or $24 \mathrm{~h}$ (for abdominoplasty); without rescue pain medication during the randomized treatment period; without early discontinuation of study medication for any reason; without reaching the study medication dosing limit. $* P$ vs. placebo (Hochberg adjusted), $C I$ confidence interval

cumulative dose was not statistically different between the $0.35 \mathrm{mg}$ and $0.5 \mathrm{mg}$ demand-dose regimens. The average number of supplemental doses was low across all treatment regimens but was highest in the placebo and the oliceridine $0.1 \mathrm{mg}$ regimens. For oliceridine, the average number of demand doses decreased as the nominal demand-dose regimen value increased.

Table 1 Exposure by treatment regimens from pooled phase III controlled studies

\begin{tabular}{|c|c|c|c|c|c|}
\hline \multirow[t]{2}{*}{ Parameter } & \multicolumn{3}{|c|}{ Oliceridine demand dose } & \multirow[t]{2}{*}{ Placebo $(n=162)$} & \multirow{2}{*}{$\begin{array}{l}\text { Morphine } 1 \mathrm{mg} \\
(n=158)\end{array}$} \\
\hline & $0.1 \mathrm{mg}(n=153)$ & $0.35 \mathrm{mg}(n=158)$ & $0.5 \mathrm{mg}(n=159)$ & & \\
\hline \multicolumn{6}{|c|}{ Number of demand doses } \\
\hline Mean (SD) & $110(80)$ & $94(69)$ & $79(62)$ & $81(72)$ & $48(43)$ \\
\hline Median (Min, Max) & $87(2,314)$ & $74(2,317)$ & $62(0,305)$ & $61(0,295)$ & $35(0,246)$ \\
\hline \multicolumn{6}{|c|}{ Number of supplemental doses } \\
\hline Mean (SD) & $2.6(3.6)$ & $1.3(2.5)$ & $0.8(2.1)$ & $1.8(1.9)$ & $0.5(1.0)$ \\
\hline Median (Min, Max) & $1(0,20)$ & $0(0,17)$ & $0(0,13)$ & $1(0,9)$ & $0(0,9)$ \\
\hline \multicolumn{6}{|c|}{ Cumulative exposure (mg) } \\
\hline Mean (SD) & $14(10)$ & $35(25)$ & $42(32)$ & 0 & $53(44)$ \\
\hline Median (Min, Max) & $11(2,48)$ & $27(2,120)$ & $33(2,160)$ & 0 & $40(4,268)$ \\
\hline
\end{tabular}

$S D$ standard deviation, $\min$ minimum, $\max$ maximum 


\subsection{Respiratory Safety}

Parameters related to respiratory safety in the pooled population are shown in Table 2. The incidence of RSEs increased progressively with increasing demand-dose regimens of oliceridine: $4.6 \%, 15.2 \%$, and $18.2 \%$ with $0.1 \mathrm{mg}, 0.35 \mathrm{mg}$, and $0.5 \mathrm{mg}$, respectively. These values were lower than the incidence reported with morphine $(22.8 \%)$, representing a relative risk reduction of $33 \%$ with the oliceridine $0.35 \mathrm{mg}$ demand dose and $20 \%$ reduction with the oliceridine $0.5 \mathrm{mg}$ demand dose compared to morphine.

The proportion of patients with DI due to RSE in both individual studies (Fig. 2) was higher with morphine (17.1\% bunionectomy and $25.6 \%$ abdominoplasty), while with the two comparably analgesic doses of oliceridine $0.35 \mathrm{mg}$ and $0.5 \mathrm{mg}$ had proportionately fewer patients: $7.6 \%$ and $11.4 \%$

Table 2 Respiratory safety parameters from pooled phase III controlled studies

\begin{tabular}{|c|c|c|c|c|c|}
\hline \multirow[t]{2}{*}{ Safety parameter } & \multicolumn{3}{|c|}{ Oliceridine demand dose (mg) } & \multirow[t]{2}{*}{ Placebo $(n=162)$} & \multirow{2}{*}{$\begin{array}{l}\text { Morphine } \\
1 \mathrm{mg} \\
(n=158)\end{array}$} \\
\hline & $0.1(n=153)$ & $0.35(n=158)$ & $0.5(n=159)$ & & \\
\hline Respiratory Safety Burden ${ }^{\mathrm{a}}(\mathrm{h})$ mean (SD) & $0.23(1.1)$ & $0.88(2.9)$ & $1.2(3.8)$ & $0.3(2.0)$ & $1.4(3.5)$ \\
\hline Respiratory Safety Event $^{\mathrm{b}}[n(\%)]$ & $7(4.6)$ & $24(15.2)$ & $29(18.2)$ & $5(3.1)$ & $36(22.8)$ \\
\hline Duration of RSE (h) mean (SD) & $5.1(2.0)$ & $5.8(5.1)$ & $6.6(6.8)$ & $9.9(7.0)$ & $6.2(4.9)$ \\
\hline $\mathrm{O}_{2}$ saturation $<90 \%[n(\%)]$ & $9(5.9)$ & $23(14.6)$ & $27(17.1)$ & $8(4.9)$ & $35(22.2)$ \\
\hline Respiratory rate $\leq 8 \mathrm{bpm}$ & 0 & $5(3.2)$ & $7(4.4)$ & $1(0.6)$ & $12(7.6)$ \\
\hline Dosing interruption due to $\operatorname{RSE}[n(\%)]$ & $5(3.2)$ & $22(13.9)$ & $24(15.1)$ & $3(1.9)$ & $34(21.5)$ \\
\hline Patients receiving supplemental $\mathrm{O}_{2}[n(\%)]$ & $7(4.6)$ & $23(14.6)$ & $28(17.6)$ & $5(3.1)$ & $36(22.8)$ \\
\hline Discontinuation for respiratory $\mathrm{AE}[n(\%)]$ & 0 & $4(2.5)$ & $7(4.4)$ & $1(0.6)$ & $5(3.2)$ \\
\hline
\end{tabular}

$S D$ standard deviation, $b p m$ beats per minute, $A E$ adverse event

${ }^{a}$ Respiratory safety burden experienced by patients was calculated as the mathematical product of the incidence of a defined set of observed respiratory safety events (RSEs) multiplied by the mean expected cumulative duration of these events (in hours)

${ }^{b}$ Monitoring of RSE included concurrent assessment of continuous $\mathrm{O}_{2}$ saturation, stopwatch-timed respiratory rate for a full minute, and completion of the Moline Roberts Pharmacologic Sedation Scale (MRPSS)

(a)

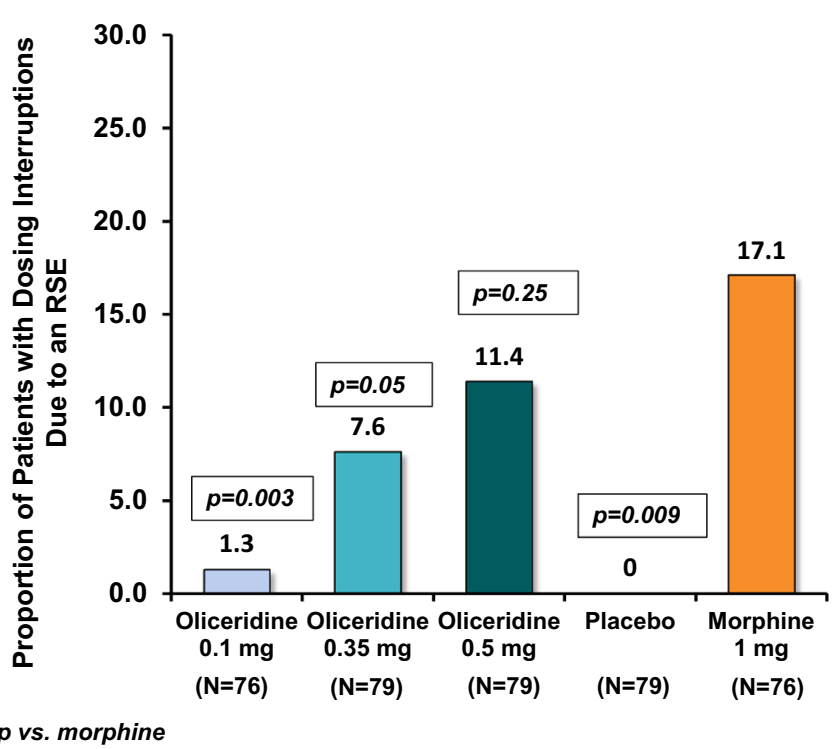

Fig. 2 Proportion of patients with dosing interruptions due to a respiratory safety event (RSE) from the phase III controlled trials. The proportion of patients with a dosing interruption due to RSE by treat- (b)

Soft Tissue (Abdominoplasty)

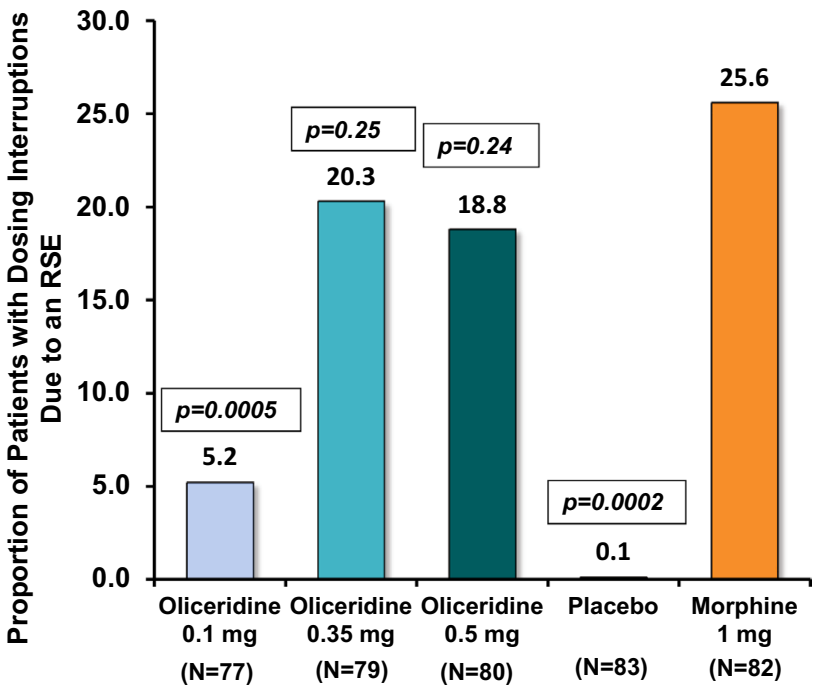

ment group is shown. a Hard tissue (bunionectomy) and b soft tissue (abdominoplasty) study. Percentages are based on the number of patients in each treatment group 
(bunionectomy), and 20.3\% and 18.8\% (abdominoplasty), respectively. The proportion of patients with DI due to RSE in the pooled population was also greater with morphine (21.5\%) compared with the oliceridine demand-dose regimens (0.35 mg: $13.9 \%, 0.5 \mathrm{mg}: 15.1 \%)$ (Table 2). As seen in Fig. 3, which depicts individual dosing patterns, there were fewer DIs with oliceridine than morphine in the pooled data as well as in the individual studies. The proportion of patients with any DI increased with increasing demand-dose oliceridine regimens from $0.1 \mathrm{mg}$ to $0.5 \mathrm{mg}$ in the individual controlled studies, $(0.1 \mathrm{mg}$ : $0.8 \% / 3.9 \%$; $0.35 \mathrm{mg}$ : 3.5\%/13.3\%; $0.5 \mathrm{mg}: 6.4 \% / 14.7 \%$ ). The proportion of patients with any DI was lower for all doses of oliceridine, ranging in relative risk reduction from $41 \%$ with the $0.35 \mathrm{mg}$ demand dose to $29 \%$ with the $0.5 \mathrm{mg}$ demand dose, compared with morphine (Fig. 4). Likewise, the CDDI was also lower with all the demand doses of oliceridine in the hard and soft tissue individual studies $(0.1 \mathrm{mg}: 0.02 \mathrm{~h} / 0.05 \mathrm{~h}$; $0.35 \mathrm{mg}: 0.1 \mathrm{~h} / 0.4 \mathrm{~h}$; $0.5 \mathrm{mg}: 0.8 \mathrm{~h} / 0.8 \mathrm{~h})$ compared to the morphine $1 \mathrm{mg}$ demand dose (0.9 h/1.2 h) (Fig. 5).

A similar pattern was observed for the proportion of patients experiencing an oxygen saturation level $<90 \%$. The incidence of oxygen desaturation was lower with oliceridine compared with morphine (Table 2), with a relative risk reduction of $34 \%$ in the oliceridine $0.35 \mathrm{mg}$ demand dose, and $23 \%$ in the oliceridine $0.5 \mathrm{mg}$ demand dose, compared with morphine.

\section{Discussion}

Use of progressively higher doses of conventional opioids such as morphine can result in an increased risk for the development of respiratory depression when used to manage postoperative pain [13]. These respiratory events can also have a prolonged course due to the delayed appearance and persistence of active metabolites, an event that can be further aggravated in patients with organ system failure. For example, the delayed appearance of the active metabolite of morphine, morphine-6-glucuronide, in patients with hepatic dysfunction is known to contribute to the accumulating analgesic effect of morphine and to unnecessarily prolonged episodes of respiratory depression [14]. Moreover, certain patient populations, including the elderly, morbidly obese, patients with sleep apnea, the very young, or patients with renal disease or neurologic disease are considered to be at higher risk for these respiratory complications $[13,15]$.

Although there is an increased awareness of the need to minimize the risk of OIRD, there are challenges associated with the clinical assessment of this postoperative complication [16]. Most significantly, there is no standardized definition of OIRD, and many studies reporting prevalence of this outcome have utilized definitions ranging from the requirement of naloxone to reverse OIRD to observations of changes in breathing frequency and/or oxygen saturation $<90 \%[3,13,16]$. This variability in the definition of OIRD and the assessment methodology used clearly influences the reported incidence, with an incidence rate of $0.3(0.1-1.3) \%$ using requirement for naloxone and 17 (10.2-26.9) \% using oxygen saturation $<90 \%$ as an indicator [17]. Clinically concerning symptoms of bradypnea or hypoxemia are typically used to characterize earlier grades of respiratory compromise [3]. In one study, early hypoxemia (defined as oxygen saturation $<90 \%$ ) was common and reported among $20 \%$ of postoperative patients, with prolonged episodes extending for $1 \mathrm{~h}$ or longer reported in $37 \%$ of patients, and with most of these episodes largely undetected during routine nursing care [18]. Undetected hypoxemia is a serious safety concern. The Anesthesia Patient Safety Foundation (APSF) recommends continuous monitoring with routine pulse oximetry and capnography in all patients prescribed opioids [19]. Indeed, in the recently completed PRODIGY trial, which attempted to detect OIRD using continuous cardiorespiratory monitoring (heart rate [HR], oxygen saturation $\left[\mathrm{SpO}_{2}\right]$, end-tidal carbon dioxide [etCO2] and respiratory rate [RR]) [20], rates of OIRD as high as $46 \%$ were reported [21].

The heterogeneity in the reported incidence of OIRD clearly indicates that these are multifactorial events, and defining them based on a single criterion may not be adequate [16, 22]. RSB as an endpoint, introduced for the first time in the oliceridine pivotal trials, required application of trained clinician judgment to detect each RSE. On the other hand, the metrics used to measure RSE, including respiratory rate or oxygen saturation, are single-measure readings that can be confounded by patient factors such as medical co-morbidities and the need to provide clinical relief by the administration of supplemental $\mathrm{O}_{2}$ [16]. Thus, despite the unique mechanism of action of oliceridine, any difference that potentially exists in reducing respiratory events compared with morphine and observed in earlier clinical trials $[10,23]$ may not have been fully delineated in the phase III studies using these measures alone. Of note, neither studies enrolled patients with medical illness co-morbidities based on protocol exclusion criteria. Furthermore, although the use of supplemental oxygen was allowed, the proportion of patients requiring such use was lower in the oliceridine treatment groups compared to the morphine group [11, 12].

In routine clinical treatment settings, dose reduction, interruption, or discontinuation are among the most immediate and unambiguous measures employed to address adverse events. Therefore, the use of DI as a surrogate measure to evaluate the "respiratory safety profile" of oliceridine can be thought of as a pragmatic, verifiable indicator compared to the subjective assessment endpoints used in the RSB construct. In this post hoc analysis of the two 
Fig. 3 Individual dosing patterns and interruptions by nominal dose for each patient in the bunionectomy and abdominoplay phase III controlled studies. a Hard tissue (bunionectomy) study. b Soft tissue (abdominoplasty) study. c Pooled data. The duration in the hard tissue study was $48 \mathrm{~h}$ and in the soft tissue study was $24 \mathrm{~h}$. Pooled data used a cut-off at $24 \mathrm{~h}$. Temporary interruptions are indicated by red bars; and permanent interruptions are indicated by solid black bars. In each figure, graphs are represented by treatment regimens. Each row in the graph represents one patient. A significantly higher proportion of patients in the placebo group in both studies $(77 \%$ in the bunionectomy study and $43 \%$ in the abdominoplasty study) used rescue pain medication, and is reflected here as receiving less demand dosing in this group. In the hard-tissue study (a) no patients treated with placebo and one patient treated with oliceridine $0.1 \mathrm{mg}$ had a dosing interruption. There was an increase in the number of dosing interruptions with the oliceridine $0.35 \mathrm{mg}$ (six patients) and $0.5 \mathrm{mg}$ (ten patients) treatment regimens. Fifteen patients in the morphine treatment regimen had a dosing interruption. In the soft-tissue study (b) three patients treated with placebo and five patients treated with oliceridine $0.1 \mathrm{mg}$ had a dosing interruption.

There was an increase in the number of dosing interruptions with the oliceridine $0.35 \mathrm{mg}$ (17 patients) and $0.5 \mathrm{mg}$ (18 patients) treatment regimens. Twenty-four patients in the morphine treatment regimen had a dosing interruption

\section{(a) Hard-Tissue (Bunionectomy)}

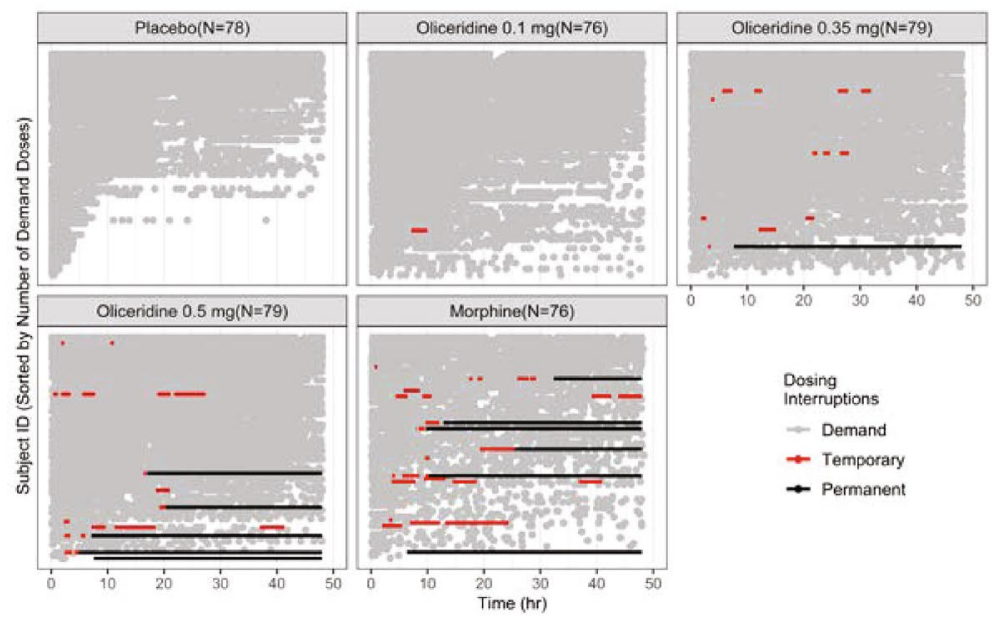

\section{(b) Soft Tissue (Abdominoplasty)}
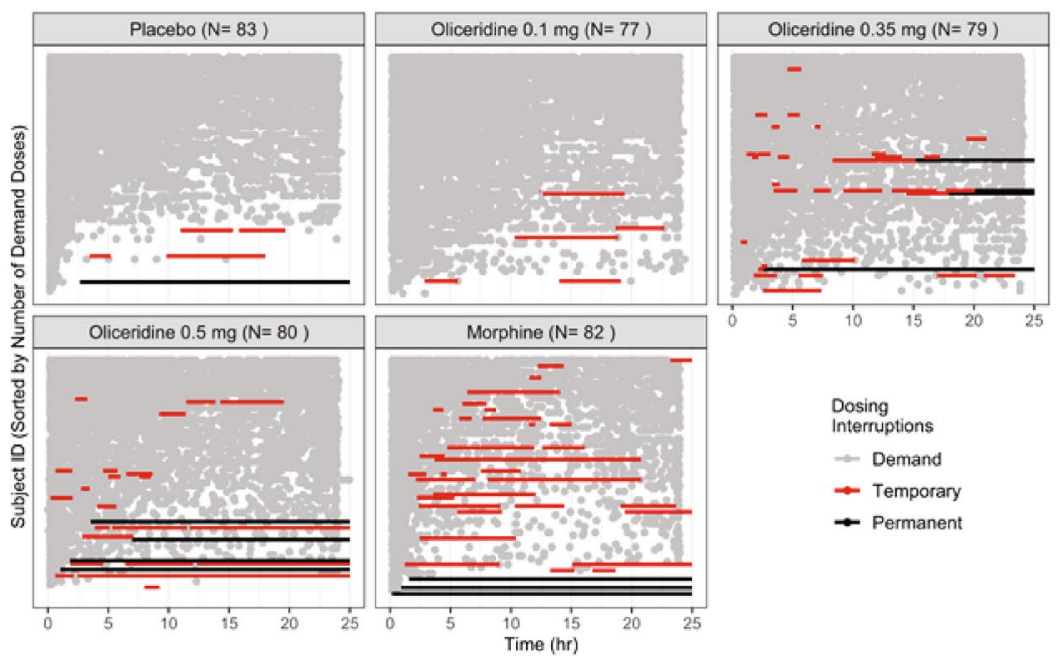

(c) Pooled data
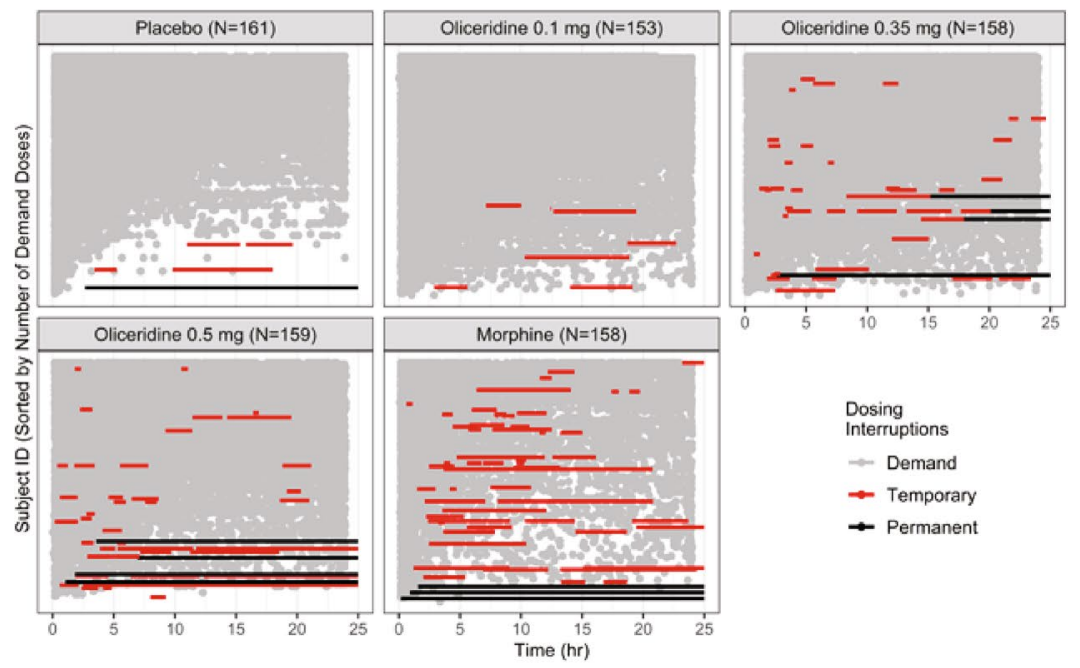


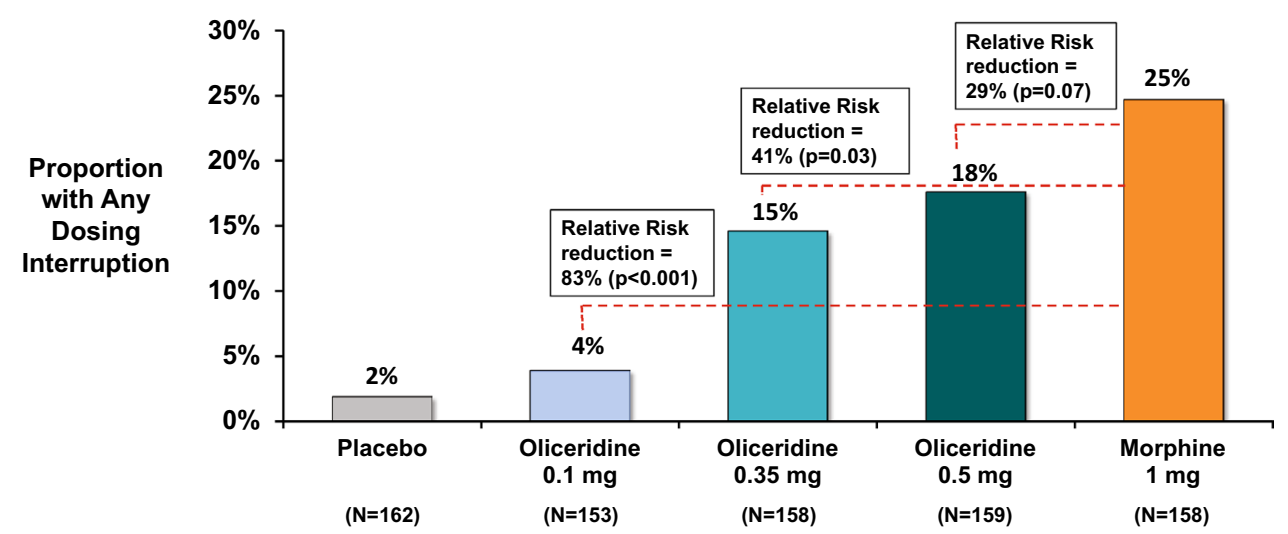

Fig. 4 Proportion of patients with any dosing interruptions from pooled data of the phase III controlled trials. Data shown are pooled from the two phase III studies, hard-tissue (bunionectomy) and soft tissue (abdominoplasty). The relative risk reduction vs. morphine is shown in the figure. In the hard tissue study, the proportion of patients with any dosing interruptions was low and similar in the oliceridine $0.1 \mathrm{mg}$ and placebo regimens $(1.3 \%$ and $0 \%$ of patients, respectively). The proportions in the 0.35 and $0.5 \mathrm{mg}$ oliceridine treatment regimens were $7.6 \%$ and $12.7 \%$ of patients, respectively. The proportion in the morphine regimen was $19.7 \%$ of patients. In the soft tissue study, the proportion of patients with any dosing interruptions was low and similar in the oliceridine $0.1 \mathrm{mg}$ and placebo regimens $(6.5 \%$ and $3.6 \%$ of patients, respectively). The proportion in the 0.35 and $0.5 \mathrm{mg}$ oliceridine treatment regimens were $21.5 \%$ and $22.5 \%$ of patients, respectively. The proportion in the morphine regimen was $29.3 \%$ of patients (a)
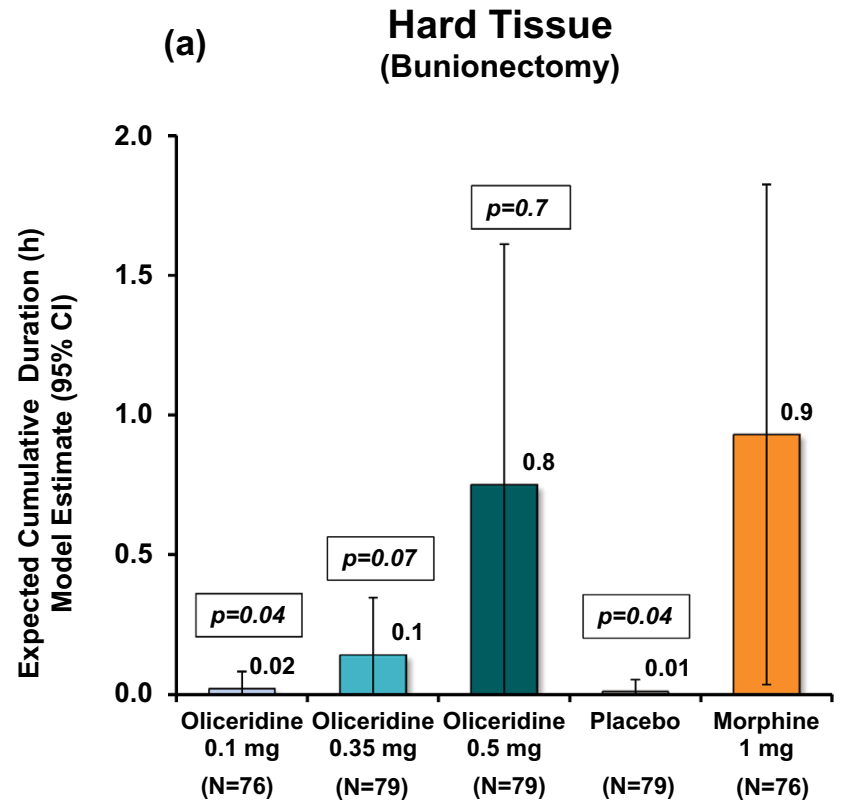

p vs. morphine

Fig. 5 Cumulative duration of dosing interruption. a Hard tissue (bunionectomy) study and b soft tissue (abdominoplasty) study. The cumulative duration of study medication dosing interruptions was modeled, and the expected cumulative duration of study medication dosing interruptions was estimated and compared between treatment groups using a zero-inflated gamma distribution. Patients who did not experience a dosing interruption were considered to have a cumulative duration of $0 \mathrm{~h}$ in the model. In the hard tissue study (a), the expected cumulative duration of dosing interruptions was similar in the oliceridine $0.1 \mathrm{mg}$ treatment regimen compared with placebo (0.02 and $0.01 \mathrm{~h}$, respectively), and the durations were greater with (b)

Soft Tissue (Abdominoplasty)

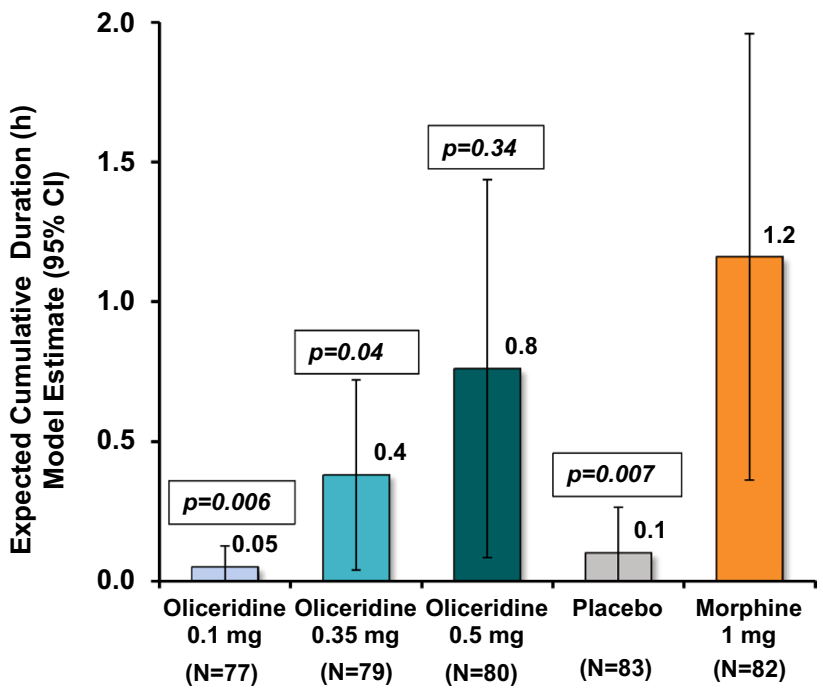

oliceridine treatment regimens 0.35 and $0.5 \mathrm{mg}-0.14 \mathrm{~h}$ and $0.75 \mathrm{~h}$, respectively. The model-based cumulative duration of dosing interruptions in the morphine regimen was $0.93 \mathrm{~h}$. The p-values shown are vs. morphine. In the soft tissue study (b), the expected cumulative duration of dosing interruptions was similar in the oliceridine $0.1 \mathrm{mg}$ treatment regimen compared with placebo $(0.05$ and $0.10 \mathrm{~h}$, respectively), and the durations were greater with oliceridine treatment regimens 0.35 and $0.5 \mathrm{mg}-0.4 \mathrm{~h}$ and $0.8 \mathrm{~h}$, respectively. The modelbased cumulative duration of dosing interruptions in the morphine regimen was $1.2 \mathrm{~h}$. The $\mathrm{p}$-values shown are vs. morphine 
phase III placebo- and active-controlled studies, the proportion of patients with a DI due to an RSE was lower for the equianalgesic doses of oliceridine $0.35 \mathrm{mg}$ and $0.5 \mathrm{mg}$ demand doses in both studies compared to morphine; $7.6 \%$ and $11.4 \%$, respectively, versus $17.1 \%$ for morphine in the bunionectomy study; $20.3 \%$ and $18.8 \%$, respectively, versus $25.6 \%$ for morphine in the abdominoplasty study. Likewise, the proportion of patients with any DI was numerically lower for all doses of oliceridine, and for the comparably analgesic demand doses of $0.35 \mathrm{mg}$ and $0.5 \mathrm{mg}$ ranged from $15 \%$ to $18 \%$, compared with $25 \%$ for morphine-treated patients. Similarly, the CDDI was also lower for the comparably analgesic doses of oliceridine $0.35 \mathrm{mg}$ and $0.5 \mathrm{mg}$ compared to morphine.

This analysis had several limitations. Of note, this was a post hoc analysis based on post-randomization events. The analysis was restricted to dose interruptions alone and dose reductions were not captured. In addition, the decision to interrupt a dose was based on the clinical judgment, and lacked standardization of a measure for when to interrupt the dosing of pain medication.

\section{Conclusion}

Using the surrogate measure of DI as a measure of "respiratory safety," these findings suggest some degree of improvement in respiratory safety with oliceridine when compared to the conventional opioid morphine in controlled studies. These data should be confirmed by future trials that evaluate equianalgesic doses and include more detailed prospective indices of respiratory compromise, including the use of continuous respiratory monitoring tools in the postoperative setting. These methods may assist in confirming and better defining the potential magnitude of differences in OIRD that may be seen with the novel IV analgesic oliceridine compared to currently available treatment options.

Acknowledgements The authors wish to thank Kanaka Sridharan, M.S. R.Ph,, an employee at Trevena Inc., for editorial assistance and creation of the figures.

Author contributions SA and AKK helped with the interpretation of the data and prepared the manuscript. MAD helped design the project, analyze and interpret the data, and revise the manuscript. DAB and CM helped with the statistical analysis. LW helped analyze and interpret the data and revise the manuscript. MJF helped collect the data, analyze the data, and revise the manuscript. All authors approved the final draft that was submitted to the journal.

Dataset availability statement The data from the two phase III studies, hard tissue (bunionectomy, APOLLO-1) and soft tissue (abdominoplasty, APOLLO-2), are held by Trevena Inc. and are not publicly available. Access to specific data sets, protocols, and reports will be considered on the basis of proposed quality and alignment with the aims of the original study.

\section{Compliance with Ethical Standards}

Funding The studies included here in the exploratory analyses (hard tissue (bunionectomy, APOLLO-1); NCT02815709 and soft tissue (abdominoplasty, APOLLO-2)) NCT02820324 were sponsored by Trevena, Inc. The post hoc analysis described here was also funded by Trevena, Inc. The funding for open-access was provided by Trevena, Inc.

Conflict of interest Mark A. Demitrack, Cathy Michalsky, Linda Wase, and Michael J. Fossler are full-time employees and stockholders of Trevena Inc. At the time the research was conducted, David A. Burt was the key statistician employed at Trevena, Inc. Sabry Ayad and Ashish K. Khanna have nothing to disclose.

Ethical approval At the time of preparation and submission of this manuscript, oliceridine, an investigational IV opioid, was not yet approved by the US Food and Drug Administration or any other governmental agencies.

Research involving human participants All procedures performed in the studies were conducted in accordance with the International Conference on Harmonisation Good Clinical Practice guidelines and ethical principles that have their origin in the Declaration of Helsinki. Protocols were approved by an Independent Ethics Committee before eligibility screening.

Informed consent Informed consent was obtained from all individual participants included in the study, as specified in the APOLLO-1 and APOLLO-2 studies.

Open Access This article is licensed under a Creative Commons Attribution-NonCommercial 4.0 International License, which permits any non-commercial use, sharing, adaptation, distribution and reproduction in any medium or format, as long as you give appropriate credit to the original author(s) and the source, provide a link to the Creative Commons licence, and indicate if changes were made. The images or other third party material in this article are included in the article's Creative Commons licence, unless indicated otherwise in a credit line to the material. If material is not included in the article's Creative Commons licence and your intended use is not permitted by statutory regulation or exceeds the permitted use, you will need to obtain permission directly from the copyright holder. To view a copy of this licence, visit http://creativecommons.org/licenses/by-nc/4.0/.

\section{References}

1. Gan TJ, Epstein RS, Leone-Perkins ML, Salimi T, Iqbal SU, Whang PG. Practice patterns and treatment challenges in acute postoperative pain management: a survey of practicing physicians. Pain Ther. 2018;7(2):205-16.

2. Shafi S, Collinsworth AW, Copeland LA, Ogola GO, Qiu T, Kouznetsova M, et al. Association of opioid-related adverse drug events with clinical and cost outcomes among surgical patients in a large integrated health care delivery system. JAMA Surg. 2018;153(8):757-63. 
3. Gupta K, Nagappa M, Prasad A, Abrahamyan L, Wong J, Weingarten $\mathrm{TN}$, et al. Risk factors for opioid-induced respiratory depression in surgical patients: a systematic review and metaanalyses. BMJ Open. 2018;8(12):e024086.

4. Lee LA, Caplan RA, Stephens LS, Posner KL, Terman GW, Voepel-Lewis T, et al. Postoperative opioid-induced respiratory depression: a closed claims analysis. Anesthesiology. 2015;122(3):659-65.

5. Hopf HW. Preventing opioid-induced postoperative hypoxemia: no simple answer? Anesth Analg. 2016;123(6):1356-8.

6. Chen XT, Pitis P, Liu G, Yuan C, Gotchev D, Cowan CL, et al. Structure-activity relationships and discovery of a $\mathrm{G}$ protein biased mu opioid receptor ligand, [(3-methoxythiophen-2-yl) methyl](\{2-[(9R)-9-(pyridin-2-yl)-6-oxaspiro-[4.5]decan- 9-yl] ethyl \})amine (TRV130), for the treatment of acute severe pain. J Med Chem. 2013;56(20):8019-31.

7. DeWire SM, Yamashita DS, Rominger DH, Liu G, Cowan CL, Graczyk TM, et al. A G protein-biased ligand at the mu-opioid receptor is potently analgesic with reduced gastrointestinal and respiratory dysfunction compared with morphine. J Pharmacol Exp Ther. 2013;344(3):708-17.

8. Raehal KM, Schmid CL, Groer CE, Bohn LM. Functional selectivity at the mu-opioid receptor: implications for understanding opioid analgesia and tolerance. Pharmacol Rev. 2011;63(4):1001-19.

9. Schmid CL, Kennedy NM, Ross NC, Lovell KM, Yue Z, Morgenweck J, et al. bias factor and therapeutic window correlate to predict safer opioid analgesics. Cell. 2017;171(5):1165-75.e13.

10. Soergel DG, Subach RA, Burnham N, Lark MW, James IE, Sadler $\mathrm{BM}$, et al. Biased agonism of the $\mu$-opioid receptor by TRV130 increases analgesia and reduces on-target adverse effects versus morphine: a randomized, double-blind, placebo-controlled, crossover study in healthy volunteers. Pain. 2014;155(9):1829-35.

11. Viscusi ER, Skobieranda F, Soergel DG, Cook E, Burt DA, Singla N. APOLLO-1: a randomized placebo and active-controlled phase III study investigating oliceridine (TRV130), a G proteinbiased ligand at the micro-opioid receptor, for management of moderate-to-severe acute pain following bunionectomy. J Pain Res. 2019;12:927-43.

12. Singla NK, Skobieranda F, Soergel DG, Salamea M, Burt DA, Demitrack MA, et al. APOLLO-2: a randomized, placebo and active-controlled Phase iii study investigating oliceridine (TRV130), a G protein-biased ligand at the mu-opioid receptor, for management of moderate to severe acute pain following abdominoplasty. Pain Pract. 2019;19(7):715-31.
13. Dahan A, Aarts L, Smith TW. Incidence, reversal, and prevention of opioid-induced respiratory depression. Anesthesiology. 2010;112(1):226-38.

14. Lotsch J. Opioid metabolites. J Pain Symptom Manag. 2005;29(5 Suppl):S10-24.

15. Gupta K, Prasad A, Nagappa M, Wong J, Abrahamyan L, Chung FF. Risk factors for opioid-induced respiratory depression and failure to rescue: a review. Curr Opin Anaesthesiol. 2018;31(1):110-9.

16. Ayad S, Khanna AK, Iqbal SU, Singla N. Characterisation and monitoring of postoperative respiratory depression: current approaches and future considerations. $\mathrm{Br} \mathrm{J}$ Anaesth. 2019;123(3):378-91.

17. Cashman JN, Dolin SJ. Respiratory and haemodynamic effects of acute postoperative pain management: evidence from published data. Br J Anaesth. 2004;93(2):212-23.

18. Sun Z, Sessler DI, Dalton JE, Devereaux PJ, Shahinyan A, Naylor AJ, et al. Postoperative hypoxemia is common and persistent: a prospective blinded observational study. Anesth Analg. 2015;121(3):709-15.

19. Weinger MB. Dangers of postoperative opioids: APSF Workshop and white paper address prevention of postoperative respiratory complications. 2007 [cited 201831 October]; http://www.apsf. org/newsletters/htm1/2007/winter/01_opioids.htm. Accessed 31 Oct 2019.

20. Khanna AK, Overdyk FJ, Greening C, Di Stefano P, Buhre WF. Respiratory depression in low acuity hospital settings-Seeking answers from the PRODIGY trial. J Crit Care. 2018;47:80-7.

21. Khanna AK, Bergese SD, Jungquist CR, et al. Prediction of opioid-induced respiratory depression on inpatient wards using continuous capnography and oximetry: an international prospective, observational trial. Anesth Analg. 2020. https://doi.org/10.1213/ ANE.0000000000004788.

22. Lynn LA, Curry JP. Patterns of unexpected in-hospital deaths: a root cause analysis. Patient Saf Surg. 2011;5(1):3.

23. Singla N, Minkowitz HS, Soergel DG, Burt DA, Subach RA, Salamea MY, et al. A randomized, Phase IIb study investigating oliceridine (TRV130), a novel micro-receptor G-protein pathway selective (mu-GPS) modulator, for the management of moderate to severe acute pain following abdominoplasty. J Pain Res. 2017;10:2413-24. 